\title{
PRIMEIRAS NOTAS SOBRE A RELAÇÃO ENTRE INDÍGENAS E 0 SERVIÇO DE PROTEÇÃO AOS ÍNDIOS NO LITORAL PAULISTA (1923-1967)
}

VLADIMIR BERTAPELI ${ }^{1}$

UNESP

\begin{abstract}
RESUMO: Entre os anos 1923 e 1967, o Serviço de Proteção aos Índios (SPI) atuou no litoral paulista por meio de um Posto Indígena: o Bananal, que, ao longo de sua história, foi chamado também de Peruíbe, Itanhaém e José de Anchieta. Nesse período, o SPI procurou concentrar e controlar os ameríndios que viviam em vários trechos da Serra do Mar em um único espaço. Em contrapartida, os indígenas assistidos fizeram frente à mencionada política indigenista. Assim, o presente artigo versa sobre a atuação ameríndia nesse Posto Indígena. Para tanto, propõe-se, aqui, articular uma etnografia histórica, coligindo as narrativas referentes ao passado dos habitantes mais idosos das atuais aldeias à pesquisa historiográfica, baseada na crítica de fontes primárias e secundárias do acervo do SPI, sob os cuidados do Museu do Índio.
\end{abstract}

PALAVRAS-CHAVE: Aldeia Bananal; SPI; ações ameríndias.

ABSTRACT: between 1923 and 1967, the Indian Protection Service (SPI) acted on the coast of São Paulo through an Indigenous Post: the Bananal, which, throughout its history, was also called Peruibe, Itanhaém and José de Anchieta. In this period, the SPI sought to concentrate and control the Amerindians who lived in several stretches of the Serra do Mar in a single space. On the other hand, the assisted Indians opposed the aforementioned indigenist policy. Thus, this article verses about the Amerindian performance in this indigenous post. Therefore, it proposes to articulate a historical ethnography, collecting the narratives referring to the past from the older inhabitants of the present villages to the historiographic research, based on the critique of primary and secondary sources of the SPI collection, under the care of the Museum of the Indian.

KEYWORDS: Aldeia Bananal; SPI; indigenous action.

\section{Introdução}

A aldeia Bananal tem um significado especial tanto para os Tupis e

\footnotetext{
${ }^{1}$ Doutorando em Ciências Sociais pela Universidade Estadual Paulista, campus de Araraquara-SP e membro do Centro de Estudos Ameríndios "Miguel Angel Menéndez" (CEIMAM). Bolsista CAPES. Email: vladbertapeli@marilia.unesp.br.
} 
Tupis-guaranis² que lá residem, ou residiram, quanto para os que vivem nos demais tekoas ${ }^{3}$ que se estendem ao longo da faixa litorânea da Serra do Mar, do Vale do Ribeira e de alguns trechos específicos do planalto paulista. Afinal, é dessa aldeia que se originou o atual conjunto de tekoas onde vivem aqueles indígenas cujo tronco linguístico é o tupi-guarani ${ }^{4}$. Certamente, fatores como dissensões entre parentelas ou lideranças, conflitos de ordem religiosa, fatores cosmológicos, etc. - conforme o que se decorreu ao longo dos séculos XIX e XX - são alguns dos elementos que desencadearam a constituição de tal cenário. Dessa forma, as histórias que contam os txeramôes e as txedjrays ${ }^{5}$ que passaram parte de suas vidas na Bananal confirmam tal afirmação, pois, de acordo com o txeramôe Domingos Mirĩ:

A minha vida lá era caçá, pescá, né. Como é a vida do índio mesmo, né. Aí acompanhava o meu tio. O meu tio fazia os mundéu. Ele reunia o pessoal lá e fazia as armadilha, né. Fazia dez, quinze armadilha. Depois ele indicava duas pessoas pra ir visitá. Aí pegava paca, tatu, pegava as caça e trazia tudo e aí dividia tudo. A estrada e o caminho, ele que chamava o pessoal da Fazenda do Afonso Reis, chamava do Koati Mirim, que era como nossos irmãos. Quando iam jogar bola, eles chamavam a gente que ia lá. Tocava forró, pandeiro, cavaquinho, violão. Se davam muito com nós. Namoravam as minhas primas... enfim, sabe como que é? (Domingos Mirĩ, Aldeia Piaçaguera, 2014).

\section{A txedjray Nambi, outra importante liderança indígena que nasceu e}

\footnotetext{
${ }^{2}$ Esses povos se reconhecem como descendentes dos grupos Tupi que habitavam aquela faixa litorânea por séculos antes do estabelecimento dos primeiros povoados luso-brasileiros. Da mesma forma, remontam a sua ascendência a laços de afinidade, co-residência e inter-casamentos passados e atuais entre parentelas Tupi e Guarani.

${ }^{3}$ A partir dessa categoria nativa, os Guarani afirmam que este é o território pelo qual eles expressam sua cultura e seus costumes e onde é possível realizar o seu modo de ser, o tekó. Além disso, o território guarani seria formado pelos inúmeros pontos de parada e pelos tekoa, que interagem entre si através de relações sociais, políticas e de parentesco, o que implica uma constante circulação. Ademais, um tekoa também é formado por um conjunto de parentes de uma família extensa (matriarcal ou patriarcal), que tem como referencial uma personalidade de prestígio (MELIÀ, 1990; LADEIRA, 1992 e 2007).

${ }^{4}$ Hoje, são 14 as aldeias formadas pelos Tupi e Tupi-guarani, situadas em diversas regiões de São Paulo, sobretudo no Litoral Paulista e no Vale do Ribeira: a Aldeia Bananal, a TI Piaçaguera (que contempla a Aldeia Piaçaguera, Nhamandu Mirim, Tabaçu Reko Ypy e Kwaray, em Peruíbe); a Aldeinha, em Itanhaém; a Aldeia Djakoaty, em Miracatu; Capoeirão ou Itariri, em Itariri; Itaóca, em Mongaguá; Morro dos Barbosas, em Paranapoã, e Morro do Saquaré, em São Vicente; Ribeirão Silveira, em São Sebastião/ Bertioga/Salesópolis; Renascer, em Ubatuba e, no interior paulista, a TI Araribá, em Bauru, e a Aldeia Pyahú, em Barão de Antonina (LADEIRA, 2015).

${ }^{5}$ Avô e avó, ou "os mais velhos da aldeia", na língua tupi-guarani.
} 
cresceu na aldeia Bananal e em suas proximidades e que, atualmente, vive com seus parentes na aldeia Djaikoaty, cuja localização está nas imediações do município de Miracatu, situado no Vale do Ribeira, lembra que:

A minha lembrança dá saudade, viu! É porque é uma coisa que me criei na casa de reza, na owguatsu. E junto com minha mãe, toda noite, a gente ia pra lá rezar. E acabava reza, porque lá amanhecia né, ia até pelas cinco, seis horas da manhã. A gente chegava em casa, ia pescar, a minha mãe pegava o covo ia pra cachoeira pescar, trazia um peixe, uma banana, preparava. Depois a gente ia pra roça. Quando era noite, voltava de novo pra casa de reza. [...] Quase todo mundo ia pra lá. Porque é uma coisa que fazia bem pra gente. Se ficava doente ia lá, o txiramôi dava cachimbarada em nós e a gente sentia bem, né. Então, a gente não podia deixar de ir, né. Então, toda noite a gente ia pra lá rezar com o baikuá. Txiramôi pra nós é os mais velhos. [...] O baikuá é o que fica lá [na casa de reza]. E como a gente se misturou assim com os Guarani [Mbyá], e eles né "txiramôi", txiramôi ficou. A gente perdeu um pouquinho. Esqueceu um pouco, né. Mas pra nós é baikuá. Tio Bento. Mas antes dele tinha, que era outro tio, Xanju, acho que o tio Arnaldo, Jijokó. Então, por último ficou o tio Bento (Nambi, Aldeia Djaikoaty, 2014).

Mas, além de ser o ponto originário de muitas famílias tupi e guarani, o espaço da aldeia Bananal, no início dos anos 1920, também foi aproveitado pelo Serviço de Proteção aos Índios (SPI) para concentrar aqueles que habitavam as várias localidades da Serra do Mar e, assim, promover a integração e a assimilação dos indígenas à sociedade nacional.

É seguro que as lembranças desses idosos, assim como a de outros indígenas, e os documentos escritos (cartas, relatórios, telegramas, ofícios, etc.) acumulados nestes anos de história oferecem subsídios que permitem problematizar o que foi a vida ameríndia sob a tutela do SPI. Tendo em vista esses e outros elementos, a proposta deste artigo é apresentar e discutir a atuação ameríndia nos Postos Indígenas do SPI, especialmente o caso do PI Bananal - que, ao longo de sua história, recebeu denominações como Itanhaém, Peruíbe e José de Anchieta -, situado ao sul litoral do estado de São Paulo e que, entre 1923 e 1967, 
respondia também pela aldeia homônima e pelas Itariri e Rio Branco.

Para tal propósito, articula-se uma etnografia histórica ${ }^{6}$ que visa reunir narrativas ${ }^{7}$ referentes ao passado dos habitantes mais idosos, os txeramôes e as txedjrays, das atuais aldeias Tupi e Tupi-guarani e à pesquisa historiográfica, baseada na crítica de fontes primárias e secundárias do acervo do SPI ${ }^{8}$, atualmente sob os cuidados do Museu do Índio. Mas, devemos salientar que não se pretende aqui submeter as fontes orais ao crivo dos registros escritos. Nesse sentido, entendemos que a melhor compreensão da história dos povos indígenas pode surgir quando se observa atentamente as interações entre as narrativas orais e os documentos escritos. Desse modo, procura-se, nesta pesquisa, seguir o que João Pacheco de Oliveira Filho (2012, p. 76) aponta: "[...] recuperar o processo histórico vivido por tal grupo, mostrar como ele refabricou sua unidade e diferença face a outros grupos com as quais esteve e está em interação".

\section{O Serviço de Proteção aos Índios}

Com a criação do SPI, em meados de 1910, o governo brasileiro se comprometia em integrar os indígenas à sociedade nacional por meio da adoção de mecanismos de controle social, como a educação formal e o trabalho, que seguia o modelo campesino. Assim, visava-se ter um reserva de mão-de-obra. Para tal propósito, seria necessário instaurar

\footnotetext{
${ }^{6}$ Como etnografia histórica, seguimos as ponderações de Sahlins (2007, p. 501), que afirma ser uma síntese da "[...] experiência de campo de uma comunidade através de uma investigação de seu passado." Também as colocações de Jean e John Comaroff (2010, p. 42), que consideram que a etnografia histórica deve ir além dos traços literários, das narrativas explícitas, das exegeses, até mesmo do argumento. Assim, não se pode contentar com a prova documental, pois "[...] os próprios cânones fazem parte da cultura do modernismo global - são tanto objetos como meios de investigação.” E, como salientam Price (1983) e Comaroff \& Comaroff (1992), os arquivos têm despertado hoje o interesse dos antropólogos pelo fato de abrigar marcas e inscrições a partir das quais eles próprios devem ser interpretados.

${ }^{7}$ Como se verificará nas próximas páginas, justificamos logo de início que o motivo de haver poucas fontes orais neste estudo se deve ao fato de que eram outras as preocupações que orientavam o trabalho etnográfico empreendido naquela época. Por conta disso, apresentamos aqui apenas os depoimentos que tratam sobre a referida questão que obtivemos em campo. Nesse sentido, a melhor compreensão da história dos povos indígenas pode surgir quando se observa atentamente as interações entre as narrativas orais e os documentos escritos.

${ }^{8}$ Devemos lembrar que o conjunto dessas fontes escritas é o que sobrou de um incêndio criminoso que, em junho de 1967, destruiu parte do acervo do SPI, então alocado no edifício do Ministério da Agricultura, em Brasília. Mas, segundo Rocha Freire (2014), graças aos esforços do antropólogo Carlos de Araújo Moreira Neto e de sua equipe, o Centro de Documentação Etnológica conseguiu reconstruir parte do acervo do SPI a partir da documentação local das Inspetorias e, então, reuni-los no Museu do Índio.
} 
uma política de tutela, pois a integração indígena à sociedade nacional ocorreria por meio de tal artifício (SOUZA LIMA, 1995; RIBEIRO, 1996).

Além disso, essa nova instituição indigenista deveria garantir terras, como também introduzir novas técnicas de produção e de prevenção de epidemias, uma vez que asseguraria condições básicas de vida à população ameríndia atendida. Prenunciava, ainda, que tal organização atuasse na pacificação de índios vistos como hostis através dos "núcleos de atração", na constituição de povoações para os nativos já em caminho de hábitos mais sedentários e, por fim, à formação de centros agrícolas onde, já afeitos ao trabalho nos moldes rurais, os indígenas receberiam terras para se instalar juntamente com a população rural (GAGLIARDI, 1985; RIBEIRO, 1996).

Portanto, o governo brasileiro, por meio do SPI, procurava disciplinar e controlar, através da educação escolar, de registros e cadastramentos, a circulação de ameríndios e dos seus territórios tradicionais, bem como acabar com os conflitos entre estes e os nacionais. Ademais, é importante termos em mente que a constituição de reservas foi uma forma de concentrar e estatizar riquezas (terras para a agricultura, pecuária, mineração, etc.), que a administração manteve para exploração direta ou indireta, sempre com o discurso de beneficiar os indígenas (GAGLIARDI, 1985; SOUZA LIMA, 1995).

A política de tutela para os povos ameríndios seria exercida pelo Estado por meio da Lei N. $.^{\circ} 5484 / 1918$. E sua lógica se concretizou graças à criação dos chamados "Postos Indígenas" (SOUZA LIMA, 1992 e 1995). Darcy Ribeiro (1996), embora fizesse algumas ressalvas quanto à eficácia do trabalho desenvolvido pelo Serviço, defendia a tutela pelo fato de compreendê-la como um dispositivo supostamente positivo do instituto jurídico em função da incapacidade civil relativa dos índios, estabelecida pelo $6^{\circ}$ artigo do Código Civil Brasileiro em vigência desde janeiro de 1917. Por essa inferência, a incumbência do Serviço pode ser vista logo na ata de fundação do órgão público. Desse documento, há o seguinte fragmento, reproduzido logo abaixo, em que se verifica a proposta de atuação da recém-criada instituição:

Aos sete dias do mez de Setembro de mil novecentos e dez, octogesimo nono da Independencia, vigesimo segundo da Republica, na cidade do Rio de Janeiro, 
Capital da República dos Estados Unidos do Brasil, e na sede do Ministerio da Agricultura, Indústria e Comércio, estando presentes o Ex. Sr. Ministro, os Diretores Geraes da Secretaria e demais pessoas abaixo assinadas, teve lugar a posse do respectivo Diretor Geral, o TenenteCoronel de Engenharia Candido Mariano da Silva Rondon, a instalação solene do Serviço de Proteção aos Índios e Localização de Trabalhadores Nacionais, creado e regulamentado pelo Decreto número oito mil e setenta e dois, de vinte de junho do corrente anno. [...] Com o fim de dar maior realce a esta solenidade, o Ex. Sr. Ministro entendeu, no intimo do seu affeto e de admiração pelas raras qualidades de Estadista de José Bonifácio, associar a origem da campanha redemptora do indio à promessa de sua vitória [...] (MUSEU DO ÍNDIO, ata da Fundação do Serviço de Proteção aos Índios e Localização de Trabalhadores Nacionais, 1910, n.p.).

É expressiva a referência à figura de José Bonifácio Andrada e Silva, uma vez que este era considerado, pelos seus idealizadores, o patrono do SPI, o que sinalizava à política indigenista que o novo instituto seguiria. Assim, como abordamos outrora, isso traz uma série de elementos norteadores para o indigenismo, que se configuraria dali por diante. Mas, evidentemente, é importante esclarecer que o regime de tutela desqualifica e aparta os índios da condição de cidadãos. Isso porque estes, juntamente com outros sujeitos (mulheres, negros e crianças) eram percebidos como indivíduos incompletos, em vias de "civilizar", ou seja, que careciam de abandonar a condição de "selvagens" e, como tal, não estariam ainda habilitados para o exercício da cidadania. Todavia, mesmo que os idealizadores SPI buscassem ao máximo afastar a nova instituição do campo de influência da Igreja e de tudo o que fosse referente ao período imperial, há semelhanças entre o projeto indigenista republicano e aquele conferido nos tempos do Brasil colonial e monárquico. Afinal, a concepção adotada pelos republicanos tinha por base o programa criado e desenvolvido durante o contexto colonial e imperial, uma vez que, guardadas suas particularidades, os postos indígenas eram análogos aos aldeamentos (SILVA, 2008; SOUZA LIMA, 1992 e 1995).

Assim, a iniciativa de criar uma instituição como o SPI, além de promover a assimilação e a integração, voltava-se à proteção dos ameríndios por meio da instalação de inspetorias regionais e postos de 
atração. Com isso, buscava-se remodelar as práticas de aldeamento verificadas ao longo do período colonial e imperial para a arregimentação de indígenas em um regime tutelar laico. No que se refere à sua organização, o relatório anual de 1921, que o SPI encaminha ao Ministério da Agricultura, Indústria e Comércio, com o qual mantinha vínculo, revela sua estrutura:

O Serviço possue, atualmente, seis Inspetorias, cujas sedes se encontram nas capitais dos Estados do Amazonas, do Maranhão, do Espírito Santo, de S. Paulo, do Paraná e do Mato Grosso. No estado do Rio Grande do Sul existe a administração de uma Povoação Indígena diretamente dependente desta Diretoria. Os estabelecimentos do Serviço no interior dos Estados são de número de 36 [...]. Em todos esses estabelecimentos pratica-se a agricultura e a criação de aves e de animais de grande e pequeno pórte, em alguns, a criação de gado vaccum se faz em grande escala; em váreos, funcionam escolas de primeiras lletras e aprendizado de musica e dos officios elementares de carpintaria, ferraria, etc. A influencia civilizadora e protetora de cada um delles não se limita à povos que vive dentro de suas terras, mas extende-se, por acção direta e intencionalmente instituída, às populações dos sertões circunvizinhos (MUSEU DO ÍNDIO, relatório do SPI de 1921, n.p.).

Darcy Ribeiro (1962, p. 22) comenta que o SPI atuava tanto por meio da criação de postos de atração para aqueles nativos vistos como hostis e arredios, quanto para "[...] povoações destinadas a índios já em caminho de hábitos mais sedentários e, daí, a centros agrícolas, onde receberiam uma gleba de terras para se instalarem, juntamente com sertanejos". Mas, apesar disso, deve-se enfatizar que o trabalho dos funcionários de tal órgão passou por uma série de impedimentos. Para comprovar essa afirmação, basta verificarmos uma passagem do relatório referente às atividades realizadas pelas Inspetorias:

[...] Entre essas falhas, torna-se cada vez mais rapidamente clamorosa, por ser fonte de inomináveis injustiças, a situação de impotência em que se acha o Serviço para obter dos poderes públicos, em certos Estados, que respeitem e façam respeitar o direito de propriedade dos índios sobre as terras que thes pertencem (BIBLIOTECA NACIONAL, relatório do SPI de 
Vladimir Bertapeli - Primeiras notas sobre a relação entre indígenas e o Serviço de Proteção....

1921, n.p.).

Dentre os elementos do documento, destacam-se a escassez orçamentária, as condições desfavoráveis para o exercício da função e o choque de interesses com as autoridades locais. Com isso, percebe-se que não eram favoráveis as condições de trabalho para os funcionários dos postos indígenas.

\section{Na costa litorânea paulista: os indígenas e o SPI}

Nas terras litorâneas, onde estão três das cidades mais antigas de São Paulo (São Vicente, Santos e Itanhaém), o SPI iniciava suas atividades com a instalação de um "posto de proteção" nos arredores da aldeia Bananal9. O motivo para tal empreendimento se deve ao primeiro fracasso na tentativa de atrair as famílias ameríndias que viviam em diversos tekoas ao longo da Mata Atlântica para o Posto Indígena Araribá10, no interior de São Paulo. Além disso, lembremo-nos que, na costa oceânica, existiram os aldeamentos de São João Batista de Peruíbe, próximo à Bananal, e de Itariri, no Vale do Ribeira. Nesse espaço geográfico, conforme os estudos de Petrone (1992), havia uma aldeia pré-cabraliana onde, em 1576, foi instituído um aldeamento, o chamado São João Batista de Peruíbe; mais ao sul, já no Vale do Ribeira, o aldeamento Itariri foi fundado em 1820. Os descendentes destes "índios aldeados", sobretudo dos grupos Tupi11, permaneceram naquelas cercanias com a população não indígena e com os grupos Guarani ${ }^{12}$ que se estabeleceram no final do

\footnotetext{
${ }^{9}$ Lembrando que, até 1950, aquela região pertencia ao município de Itanhaém.

${ }^{10}$ O PI Araribá foi o local escolhido pelas autoridades do Serviço para alocar os índios que viviam em determinados pontos de São Paulo. Dessa feita, tal espaço passou à categoria de Povoação Indígena e, mais tarde, de Posto Indígena. Portanto, até então, essa era a única reserva oficial destinada a manter os Guarani que viviam em São Paulo, fossem oriundos do Oeste Paulista, ou da região de Itaporanga, Paranapanema, Itanhaém e Vale do Ribeira (TIDEI DE LIMA, 1978; ANTUNHA BARBOSA, 2013).

11 O termo Tupi foi utilizado para designar de forma genérica os grupos formados pelos Tamoio, Tupinambá, Tupiniquim e Tabajara, cujo habitat veio a ser posteriormente invadido pelos portugueses (MÉTRAUX, 1979; CHAMORRO ARGÜELLO, 2008). Estes dominavam a faixa litorânea que compreendia desde Iguapé, em São Paulo, até a costa do Ceará, enquanto os Guarani habitavam a bacia Paraná-Paraguai e o litoral brasileiro, desde a Lagoa dos Patos-RS até Cananeía-SP (FERNANDES, 2006; FAUSTO, 2010).

${ }^{12}$ Os Guarani, que ocupavam uma área que se estendia desde a bacia Paraná-Paraguai até o litoral - da Lagoa dos Patos, no Rio Grande do Sul, à Cananéia, em São Paulo, provavelmente são descendentes dos Tañyguá, Oguauíva e Apapocúva, grupos Guarani que seguiam seus líderes religiosos, os chamados karaí, para o litoral na tentativa transpor o oceano e, assim, chegar a Yvy Marãey, a Terra Sem Mal ${ }^{12}$. Assim, em
} 
século XIX e nos primeiros decênios do século XX.

Portanto, em meados de 1923, os funcionários do Serviço iniciavam o trabalho de contatar, identificar e concentrar os índios que encontravam à medida que avançavam pelas matas ciliares dos rios Preto, Branco e Arararú, nas imediações de Itanhaém (BIBLIOTECA NACIONAL, Relatório de 1923). Mas, assim como aconteceu no PI Araribá, não foi fácil levar adiante tal missão. Pois, entre os nativos que relutaram em ir para tal aldeia, estavam os antepassados dos atuais Guarani que vivem na aldeia do Rio Branco, também localizada no município itanhaense. Na sequência, no ano de 1925, algumas famílias guaranis estabeleceram-se nas proximidades do Rio Branco, um dos principais rios que formam a bacia hidrográfica de Itanhaém e região, e vieram a fundar naquele local a aldeia do Rio Branco. Não obstante, existiram tentativas de trazê-los para a aldeia Bananal. Conforme a missiva de Victor Tonollier,

Quanto aos índios aldeados em Rio Branco, continua como quando eu encontrei na minha primeira visita que a eles fiz e que já comuniquei em relatório a essa I. R., ou seja, desobedientes e dispostos a não voltarem para Bananal, assim como irem a capital sem minha autorização. [...] estes não aceitam nada fornecido por este Pôsto e negam-se a dar o nome para fins de recenciamento, não obstante, tenho continuado com o mesmo objetivo que trassei, o de convencê-los que este Pôsto tem a finalidade de ampará-los em tudo que necessário for, dentro do pocivel. Acontece, porém, que a Polícia da capital Paulista, instrui-os, segundo o que disem, no sentido não se afastarem das terras onde teem suas casas, porque o Governo vai mandar medir aquelas terras e entregar a eles (MUSEU DO ÍNDIO, carta de 1949, n.p.).

No relatório de 1928, os servidores do SPI responsáveis por tal missão encontraram uma série de dificuldades, entre as quais o "[...] apêgo as antigas moradas e circunstâncias especiais da política interna de cada grupo [...]" (MUSEU DO ÍNDIO, Relatório do SPI de 1928). Mas, nesse mesmo ano, o Serviço obteve do governo do estado de São Paulo

distintos momentos, estes Guarani saíram da região sul do Mato Grosso, no baixo do Rio Iguatemi, afluente da margem direita do Rio Paraná, e, após uma longa jornada, durante a qual vieram a constituir aldeias em Itapetininga, Itapeva da Faxina, Piraju e no Rio Verde (Itaporanga), finalmente se estabeleceram em diversos pontos do Litoral Paulista e do Vale do Ribeira (NIMUENDAJU, 1987; FERNANDES, 2006; FAUSTO, 2010). 
duzentos alqueires de terras nas proximidades da aldeia Bananal13. 0 relatório de Milton Fraga Moreira, então vereador do município de Itariri e inspetor da Diretoria de Terras e Colonização, em que ele rememora o processo de constituição de tal posto no litoral paulista, confirma tal afirmação. Conforme suas palavras,

[...] o então presidente do Estado de S. Paulo, Dr. Julio Prestes de Albuquerque, em entendimento com 0 Ministério da Agricultura, reservou por decreto no mesmo ano a área de 200 alqueires paulista de terras de cultura no município de Itanhaem, a margem do rio Bananal para ali serem aldeados todos os índios que viviam desajustados vagando pelas terras devolutas do Estado nesta região. (MUSEU DO ÍNDIO, relatório de 1953 , n.p.).

Notadamente, o governo estadual, através do Serviço de Discriminação de Terras Públicas, iniciava um processo de identificação de terras devolutas, conforme a Lei de Terras (Lei n. 601, de 18 de setembro de 1850), no território onde viviam os grupos Tupi e Guarani. Em relação às chamadas terras devolutas, tal Lei define como sendo aquelas que não estão sob o domínio de particulares, sob qualquer título legítimo, nem aplicado ao uso público federal, estadual ou municipal, estabelecendo que a aquisição de terras só seria possível por meio da compra. Segundo Manuela Carneiro da Cunha (1992), cinquenta anos após o Regulamento das Missões, a Lei de Terras reafirma a conveniência de se assentarem os indígenas.

Segundo Azanha e Ladeira (1988), após demandas de políticos locais, o SPI estabeleceu o Posto Indígena Peruíbe no município de Itanhaém em meados de 1928. Entretanto, a matéria publicada pelo jornal A Platéa, de 26 de novembro de 1930, questiona os recursos expedidos para tal posto, uma vez que suas atividades se encerraram um ano depois. Conforme o conteúdo da matéria,

Nao existindo ali o índio desde 1929, era natural que nao existisse também no orçamento de 1930. Entretanto, isto nao se deu. Como terá a Inspectoria de Índios de S. Paulo, pois, prestado contas relativas ao emprego dessa

\footnotetext{
${ }^{13}$ Decreto-Lei N. 5.484, de 27/06/1928.
} 
verba durante o periodo de $1929 / 30$ e que, naturalmente, deveria ser consumida por cotas mensais?" $E$, mais adiante, [...] o que fez o Serviço de Índios nessa Gleba por elle pedida em prol do selvícola littoriano? Ao que consta, nada la existe que possa testemunhar a acção protectora ou constructora dessa repartição do Ministerio da Agricultura. Por nao haver harmonia entre todos então agrupados que, apezar de serem da mesma nacção guarany, pertenciam a grupos differentes, resultou a mudança das levas recemchegadas para a praia de Peruybe. Entre os retirantes também nao houve accordo sobre a installação do novo acampamento, pelo que dividiram-se em dois grupos, permanecendo um nas proximidades de Peruybe, enquanto o outro viajou para a Praia Grande, sem destino quando foram encontrados pelo dr. Arens que, condoido com o estado dos viadantes, offereceu-lhes guarida em suas terras, próximas a estação da Praia Grande da E.F. Santos-Juquiá, para onde se encaminharam e formaram seu novo acampamento ( $A$ PLATÉIA, 1930 apud ANTUNHA BARBOSA, 2011, s.n.).

Por outro lado, um leitor anônimo contesta a supracitada matéria do jornal A Plateia. Tal leitor informa que o Posto Indígena existiu de fato; porém, ao invés de ter sido instalado na aldeia Bananal, "[...] foi localizado em Peruybe, isto por commodidade dos funcionários e servia de abrigo a algumas dezenas de índios guaranys sob as ordens do cap. Samuel, velho cacique dessa tribu". E, mais adiante, revela-se que o posto foi extinto

[...] sem decreto que autorizasse essa medida [...]. Os índios que ali viviam foram enviados para a Povoação Indígena do Araribá [...] onde o encarregado [...] dirige os índios com demasiada severidade. (A PLATÉIA, 1930 apud ANTUNHA BARBOSA, 2011, s.n).

Mas citemos novamente o relatório do vereador Fraga Moreira, que assinala as tentativas de se organizar um Posto Indígena na costa litorânea paulista:

Em 1933, reiniciando a descriminação de terras devolutas do Estado neste litoral, foi constatado a existência de algumas famílias de índios Guarani próximo a cabeceira do rio do Azeite, no Lote 33 da Gleba A, Zona I, Perímetro 18. Vizando mantê-los nessas terras, foi ouvida a Seção Judiciaria deste Departamento 
nessas terras, digo, naquele tempo chamado Diretoria de Terras e Colonização. O parecer foi favorável, todavia como esses índios ocupassem a tutela da Lei (Art. 6 e seu parágrafo único do Cod. Civ.) devia ser cobrado aos índios o valor das terras segundo a Lei e a época, todavia sendo eles bastante pobres as terras foram concedidas pela clausula de propriedade de títulos, algum tempo foi, digo, pela clausula do nome [...]. Enquanto se processava a expedição do título de propriedade, algum tempo foi consumido, o certo é que em 1935, antes do desfecho final, o sub-inspetor, encarregado da região, (eu ainda nao andava por aqui) pela carta em data de $11 / 8 / 35$, comunicava terem os índios abandonado as terras, deixando uma tapera e alguns pés de bananas e consultava seu superior se o lote poderia ser requerido por outros. Naquele tempo as terras eram vendidas a Cr\$ 80 por hectare - 5 anos para pagar - Para despacho do Sr. Diretor de $1 \mathrm{~h}$ de 9 do mesmo nao foi o lote caducado ou melhor tornado vago por abandono. Em 28 de fevereiro de 1936 este lote for a vendido após ser reduzido em 2 partes de 11,80 hectares cada (MUSEU DO ÍNDIO, relatório de 1953, n.p.).

Esse excerto indica o reinício do processo de levantamento das terras devolutas no estado paulista e também versa sobre a presença indígena no litoral e o interesse das autoridades locais em retomar as atividades do SPI. Aliás, nesse mesmo ano, o vereador pedia para Deocleciano de Sousa Nenê, então chefe da $5^{a}$ Inspetoria Regional do SPI, a instalação de um posto ao sul do litoral paulista:

Do que me é dado a conhecer o índio é tratado em Lei, como simples creanças ou melhor como insanos. Aceitando como certo espírito da Lei, a sua aplicação tem sido incompleta deixando, centenas de selvicolas à própria sorte, vagando como nômades em completa promiscuidade, povoando as florestas deste litoral como animais irracionais. [...] Do exposto acima, faço um apelo ao Serviço de Proteção aos Indios, crear quanto antes um Posto em Itanhaém, localizando ali um ou no próprio Aldeamento, sua Séde e destacando para lá funcionários competentes, de comprovada indoneidade, para não acontecer como já tem acontecido, de os próprios índios agredirem os funcionários, resultando o caso em que se encontra o Aldeamento (MUSEU DO ÍNDIO, carta de 1953, n.p.). 
Para além do que se pode extrair de uma primeira leitura desse trecho, que é a justificativa de instalar um Posto Indígena no litoral paulista, gostaríamos de destacar que a visão do vereador Fraga Moreira em relação aos indígenas denota uma antiga e recorrente afirmação: a de que estes, ao lado das mulheres e crianças, seriam incapazes de responder juridicamente por seus atos. Para o autor, o tratamento aos nativos previsto pela Lei14 é insatisfatório, porque estes estão "[...] à própria sorte, vagando como nômades em completa promiscuidade, povoando as florestas deste litoral como animais irracionais[...]".

No entanto, esse pedido oculta o interesse do político, assim como o de outras autoridades locais, em concentrar em um único espaço os ameríndios que viviam nas diversas aldeias e, com isso, liberar terras para seus negócios de cunho agrário e imobiliário. Esses, portanto, seriam os reais motivos de tais sujeitos exigirem a instalação de um posto na costa litorânea. Isso é também perceptível no teor de uma missiva, que o mesmo vereador encaminhara para o chefe da $5^{\text {a }}$ Inspetoria Regional e na qual revela que:

[...] na minha gestão, os índios voltaram ao lote, dando origem a minha primeira comunicação a chefia [...] tendo recebido o segundo despacho. "O Senhor Inspetor de $3^{a}$ Classe, encarregado da colonização do Litoral Sul, não deve permitir a entrada dos índios na Gleba $A$, pois os mesmos tendo abandonado o Lote 33 da Gleba A-I perderam o direito da concessão gratuita". Em 7 do 12 de 38, enderecei uma carta a polícia de Itanhaém solicitando remover esses índios para suas terras no aldeamento do Bananal, porem frisava "Outrossim solicitamos usar meios pacíficos visto a irresponsabilidade desta gente" (MUSEU DO ÍNDIO, carta de 1953, n.p.).

O trecho acima é mais uma evidência da persistência dos servidores do SPI e dos políticos locais em impor limites territoriais para os indígenas no litoral paulista. E tal documento, assim como o que indicamos anteriormente, revela os anos em que se procurou implantar o projeto de confinamento daqueles ameríndios. Aliás, esse texto também sugere a incompreensão das autoridades locais quanto à relação dos ameríndios

\footnotetext{
${ }^{14}$ Certamente ele se refere ao $6^{\circ}$ artigo do Código Civil Brasileiro, em vigência desde janeiro de 1917.
} 
com o espaço em questão. Pois, diferentemente do primeiro excerto que abre a presente seção, o vereador orientava um funcionário de $3^{\text {a }}$ Classe, encarregado da colonização do Litoral Sul, a proibir os índios de ocupar as terras na Gleba A, "[...] pois os mesmos tendo abandonado o Lote 33 da Gleba A-I perderam o direito da concessão gratuita". E, caso os indígenas não saíssem, o servidor público poderia valer-se da força policial para a desobstrução das terras. Ademais, esse episódio pauta o conteúdo da carta que Souza Nenê despachara para José Maria da Gama Malcher, então Diretor do SPI. Conforme o excerto:

Entendo que o SPI deve procurar reunir todos os índios dali, que não são muitos, nos 200 alqueires no lugar do Bananal, onde foram a eles reservada essa área, porque, querer tentar legalizar outra área de terras para esses índios, hoje, com a grande conquista de terras, principalmente naquela região, onde já não mais existem terras devolutas, ainda que posse antiga, como todo o mais são, dos índios, mas que requeridas e medidas sem o devido protesto no tempo oportuno, por parte do nosso Serviço, já estando todas loteadas, será "dar murro em faca de ponta!" O mais acertado será se procurar legalizar definitivamente os 200 alqueires no Bananal, si é que ainda não está devidamente legalizada essa área, se reorganizar o Posto, instalar uma escola, por uma pessoa capaz [...] (MUSEU DO ÍNDIO, carta de 1953, n.p.).

Além do exposto, Souza Nenê, em resposta à Diretoria do SPI, em 29 de outubro de 1953, expõe a disputa entre políticos locais pelo controle dos indígenas daquela região. De acordo com suas palavras,

Descortinou-se quais os motivos de manutenção e expulsão dos índios, e que nenhum dos homens ora credenciados servem para delegados do SPI, e eu estou ainda a favor do que deleguei poderes, Sr. Milton Fraga Moreira, não pelo fato de feito com todas as formalidades exigidas pelo Regimento, e o Sr. Cap. Muniz Barreto ser sem essas formalidades, e sim pelas informações que reputo como sendo as que estão com a verdade, e também como observador corroborado pelas informações que me prestou pessoa que me conhece o Sr. Cap. Muniz Barreto, julgo de meu dever adotar essa Diretoria que nao deve agir confiando tanto em dito sr. que se diz grande defensor dos índios, e o quanto está 
deixando transparecer, está tirando proveito da situação (MUSEU DO ÍNDIO, carta de 1953, n.p.).

Logo a seguir, reproduzimos um fragmento do depoimento do indígena Capitão Antônio Branco, que concedeu aos antropólogos Gilberto Azanha e Maria Inês Ladeira (1988) o seu ponto de vista em relação à implantação do Posto Indígena e à sua luta em assegurar a terra para seu povo.

Dei quatro viagens pro Rio de Janeiro, o coronel Nicolau Horta veio dizendo: Oh Branco, pra nós não fazer questão a contra o Governo, assim como eles venderam fica pra eles, vocês vão começar daqui pra cima. Como de fato hoje estamos aqui. Aí foi, foi, foi, quando chegou esse tempo, a gente não tinha mais lugarzinho de fazer fogo. Tá tudo tomado. Milton Fraga vendeu tudo, que aqui diz que não havia área de terra de índios. A gente, como naquele tempo não tinha o documento da área, o coronel Nicolau Horta falava que daqui pra cima, tudo esse fundo é tudo de vocês, esse terreno do Governo. Última vez, eu tava pra São Paulo, foi de novamente, quando eu, conversando, apareceu o Milton Fraga dizendo que daqui os índios tinham que abandonar. Cai tudo pra fora do Bananal. Ai como eu sou muito teimoso, e eu servi o governo no Ministro de Guerra, Rio de Janeiro, o tempo do Mal. Rondon, eu digo não, eu vou bater. Assim como arrisquei minha vida pra defender 0 nosso Governador, como é que eu não posso ter uma área de terra pra eu viver dentro dela. Que são obrigados a me dar direito. Bati última vez pro Rio de Janeiro, fui falar com o Ministério. Aí chamou o protetor dos índios dizendo que aqui tinha que ser de bem ou mal, tem que ser uma área de terra pra os índios, que eles tinham que tomar providências. Aí eu vim embora do Rio de Janeiro, eu cheguei, aí ele disse, o Ministro disse: Bom, ó Branco, pode ir-se embora que não vai acontecer nada, vai demorar mais um pouco, mas não vão acontecer nada. Espera a turma por esses quinze dias, de aparecer a turma lá pra vocês. Como de fato, quando completou 15 pra 16 dias, apareceu o tal do Itamar. Era empregado geral do Posto da Diretoria. Aí ele apareceu lá. Veio três caminhões de material pra fazer aquele posto, aquela casa de telha pra garantir a terra pros índios. E a gente não sabia como que estava aí a benfeitoria, mas dentro de, bem dizer aqui desse lugar o mais em benfeitoria estava medido pra o tal de Mario coisa lá de São Vicente. Ele tava querendo tocá os índios. Até que ele me 
ofereceu 5, 15 mil pra benfeitorias, pra eu abandonar. Ai Otavio Canguçu, que era funcionário do SPI, ele sempre vinha aí, aí eu falei, digo, tem que falar com Otavio. Se Otavio deixar, eu disse, aí eu posso abandonar. Aí eu fui em Peruíbe, que ele morava lá, eu contei a Otavio. Otavio disse: Você podia pegar esses 15 mil que ele ofereceu e depois você podia falar que eu não saio daqui. Agora, se ele tornar oferecer de novamente manda o Mario guardar os 15 mil cruzeiros e lavar, dizia, a cueca da mulher, comprar sabão. Fala mesmo. Mas parece que desta vez ele teve sorte, não fala mais comigo. Daí nunca mais apareceu e ele morreu e ficou a viúva. A viúva sempre passava por aqui, dizendo que essa terra aqui é dele. Sempre me falava: é isso aí, o seu Branco está aí por causa do policial do povo. Digo não, isto aqui está reconhecendo como meu, como é que não. Saia-se embora, não fala mais nada (CAPITÃo ANTONIO BRANCO apud AZANHA e LADEIRA, 1985, p. 47-48).

Nesse documento, há três pontos que reforçam o que expomos até o momento e que destacamos: 1) a repartição das terras devolutas, pois, conforme o trecho: "[...] assim como eles venderam fica pra eles, vocês vão começar daqui pra cima. Como de fato hoje estamos aqui. Aí foi, foi, foi, quando chegou esse tempo, a gente não tinha mais lugarzinho de fazer fogo"; 2) o interesse dos políticos pelas terras onde habitavam os indígenas, como expressa o fragmento em que o vereador Milton Fraga teria vendido "[...] tudo, que aqui diz que não havia área de terra de índios" - o que reforça a afirmação de Souza Nenê quanto à sua desconfiança sobre os políticos da região; 3) a implantação do Posto Indígena na aldeia Bananal que, segundo o Capitão, "Era empregado geral do Posto da Diretoria. Aí ele apareceu lá. Veio três caminhões de material pra fazer aquele posto, aquela casa de telha pra garantir a terra pros índios".

Ao que parece, essa situação de intermitência no Posto Indígena no litoral de São Paulo permaneceu ao longo de toda sua história. No relatório de 1964, o funcionário Ney Land revela que "Apesar do SPI ter criado o Posto José de Anchieta, ele não existe. A Aldeia, para fins de administração, está ligada diretamente à sede do SPI, em Brasília" e que "[...] não existe casa-sede. Na aldeia somente existe a casa dos índios". Mais adiante, o relatório indica que o encarregado, Octavio Canguçu, "[...] vai uma vez por mês à Aldeia, para verificar como vão as coisas, ou vai lá 
sempre quando é chamado" (MUSEU DO ÍNDIO, relatório do SPI de 1964, n.p.).

Notemos que foram várias as tentativas de implantar um Posto Indígena no litoral. Fica claro que os sucessivos nomes do mencionado posto é um indício de sua instabilidade e, ainda, que, em decorrência da resistência indígena, fracassou o projeto do SPI de alocá-los em uma única aldeia. Consequentemente, o litoral de São Paulo teve um posto e três aldeias - Bananal, Itariri e Rio Branco - que permaneceram sob os cuidados do SPI. Mesmo assim, o cotidiano desses ameríndios teve como característica a interferência dos agentes do Serviço. É o que veremos na próxima seção.

\section{A luta diária no P.I. Bananal}

Os relatórios, cartas e depoimentos serão, mais uma vez, de grande valia para entendermos - ou, pelo menos, para termos uma ideia aproximada - a atuação ameríndia em relação à política indigenista do SPI no litoral paulista. Porquanto, como ensinam Vansina (1973) e Goody (2012), a palavra escrita não substitui a fala, assim como esta não substitui aquela, mas ambas podem complementar uma à outra. Como veremos mais adiante, o conteúdo dos documentos aqui reunidos tratam de diversas questões, como a luta contra a dispersão indígena; a tentativa de sua assimilação e controle; a usurpação de seu trabalho; a corrupção dos administradores do Posto; o seu contato dos indígenas com a população local não indígena e, não menos importante, a resistência ameríndia.

Comecemos, então, pelos comentários de Victor Tonollier, funcionário recém-empossado ao cargo de encarregado do P. I. Itanhaém, sobre os nativos prenotados na aldeia Bananal naqueles primeiros anos de atuação do SPI.

Vivem mal alimentados, raquiticos e cheios de vermes. Vivem quase exclusivamente da caça, faltando-lhes, porém, iniciativas para o trabalho de lavoura. Agóra, com a minha administração, que tem sido psicológica e paciente, eles já estão se integrando no serviço, o qual 
tem sido continuado e gradativo. Os que encontrei na Aldeia e que foram pouquíssimos, bem como os que tenho trazido para a mesma, são obedientes e atenciosos (MUSEU DO ÍNDIO, carta de 1949, n.p.).

À primeira vista, o fragmento dessa carta remete à tendência salvacionista do funcionário em relação ao modo de vida dos indígenas contatados. Estes, por conseguinte, são descritos como "mal alimentados, raquiticos e cheios de vermes. Vivem exclusivamente de caça", não afeitos ao "trabalho em lavoura" e que, por causa do trabalho que o funcionário vinha desenvolvendo, rapidamente estariam integrados à sociedade nacional. Porém, outro mote importante dessa fonte primária é a passagem na qual o encarregado registra que "os que tenho trazido são obedientes" - o que confirma a presença de índios dispersos, ou melhor, fora do alcance do SPI. Quando avançamos um pouco mais na leitura, deparamo-nos com algumas informações pertinentes quanto às dificuldades que seus servidores tiveram quando tentaram implantar o modo de produção rural na aldeia Bananal, segundo o modelo que apregoava pelo Serviço:

Com referência as roças, tenho a informar-vos que continuo determinando as suas plantações, bem como a derribada de capoeiras finas, incentivando, desta forma, o trabalho, o único capaz de lidar com a grande miséria que ainda ha bem pouco existia aqui (MUSEU DO ÍNDIO, carta de 1949, n.p.).

Não obstante, o conteúdo da missiva que segue expõe as dificuldades presentes no cotidiano do Posto. Logo, o servidor público ainda expõe que:

[...] Vendo-me cercado de perguntas dos índios daqui e dos que veem de fóra, sôbre o fornecimento de generos e roupas para eles, alego sempre a mesma coisa: a minha Inspetoria não tem verba, o que eles não creiam, chegam a pensar que eu estou ficando com a verba "de auxílio aos índios" - sobre a existência dessa verba, eles souberam no Rio de Janeiro - deixando-me numa situação desfavorável, como se vê pelo exposto (MUSEU DO ÍNDIO, carta de 1949, n.p.). 
Em tal passagem, principalmente onde se lê "dos índios daqui e dos que veem de fora", pode-se observar a circulação, aparentemente frequente, de moradores próximos e visitantes, o que sugere que eram mantidas relações entre os ameríndios e a população local que vivia próxima à aldeia. Ademais, ainda se pode extrair de tais documentos a insistência das autoridades que dirigiam o posto em controlar a vida dos ameríndios. Por exemplo, no ano de 1949, o inspetor do PI Itanhaém apresenta à $7^{\text {a }}$ Inspetoria Regional de Curitiba um relatório no qual, além de solicitar equipamentos agrícolas, material escolar e medicamentos, aborda as atividades que se realizaram naquele ano. Dentre elas, destacamos:

Levo a conhecimento desta I. R. que aproveitei minha ida à S. Paulo para fazer uma visita à RÁDIOS e JORNAIS de Santos, São Vicente e Guarujá, solicitando por meio destes veículos, não dar bebidas alcoolicas aos índios, bem como não comprar nada deles sem minha ordem Radio Cultura São Vicente Jornal, Radio Guarujá, Radio Antlantica (PRG7) de Santos - pois os índios teem, agora o amparo do S.P.I., o qual está disposto punir na forma da lei os infratores. Confesso que apesar do povo não gostar dos índios, tem cooperado grandemente comigo no sentido de evitar que eles continuem se degradando, como quando estavam sem amparo (MUSEU DO ÍNDIO, relatório de 1949 , n.p.).

Afora o uso de tais canais de comunicação, os funcionários do SPI ainda se valiam dos serviços municipais. Em outubro de 1949, a prefeitura de Itariri publicou um edital em que se proibia o comércio entre não indígenas e indígenas, bem como a venda para estes de bebidas alcoólicas. A prefeitura de Itanhaém, em novembro daquele mesmo ano, também lançou uma nota com o mesmo teor (MUSEU DO ÍNDIO, edital de 1949). No entanto, não foram apenas essas as intervenções dos inspetores do Serviço sobre a vida indígena: elas também estavam presentes no controle da circulação de indígenas no meio urbano, bem como da venda de artesanato.

Ainda há bem poucos dias estive lá pela segunda vez e já os encontrei mais agradáveis para comigo, embora não aceitem ordem minha, ordem essa que é de não ir sem licença a Capital, mas eles alegam que só recebem 
ordem do Delegado de S. Paulo, diante disso estou para me dirigir ao dito Delegado, pedindo somente que ele não permita, digo, dê base para isso (MUSEU DO ÍNDIO, carta de 1950, n.p.).

Quanto a isso, os indígenas também reagiram ao controle do poder estatal, que procurava exercê-lo por meio dos seus agentes. Para ilustrar essa informação, valemo-nos mais uma vez do depoimento de Domingos Mirĩ:

[...] o delegado de repressão à vadiagem no estado de São Paulo, ali, lá perto da estação da Sorocabana, nós fomos lá porque estavam prendendo as mercadorias todas, artesanato né, porque quem fazia essas coisas era considerado malandro, vagabundo, vadio... aí nós fomos lá. Sabe o que aconteceu? Quando fomos falar com o delegado regional ele falou assim: "Escuta, vocês conhecem o Arnaldo?" O meu pai falou assim: "Esse é meu irmão". Puta merda, meu, era amigão do meu tio! (Domingos Mirĩ, Aldeia Piaçaguera, 2014).

O controle também estava na regulação do material doado aos próprios índios. Pode-se evidenciar tal colocação pelo relatório de Tonollier:

Informo que o material agricula recebido como doação pelo Doutor Almir Custódio Ferreira, de Santos, está a disposição dos índios, porém, depositado neste Pôsto e recolhido ao mesmo após usado, afim de evitar que os referidos índios os venda [...] o dinheiro da mesma é empregado em 'pinga', caninha, resultando daí grandes e sérias consequências que vêm trazer muitos embaraços a minha administração, como ocorreu ha dias na Aldeia de Itariri (MUSEU DO ÍNDIO, carta de 1950, n.p.).

A insubordinação dos indígenas assistidos também está presente nas fontes primárias que aqui trabalhamos. Mais uma vez citamos uma carta, de 12 de janeiro de 1950, em que o servidor Victor Tonollier faz referência à rebeldia nativa:

Quanto aos meus índios, estão difíceis de entrarem no eixo, pois de quando em vez, procuram pretextos infundados, para fazerem reclamações e, negarem-se a 
trabalhar, alegando não terem alimentação para suportarem o serviço, daí minha pressa em vender a caxêta, cujo produto monetário (uma parte apenas) reverterá em benefício deles, fazendo-os proseguirem com roças costeada por este Pôsto. [...] tomar providências, já solicitadas várias vezes, que diz respeito a retirada de quatro índios rebeldes: João Samuel, André Samuel, Bento Samuel e "Zizi" Samuel, nada poderá se fazer em benefício dos demais índios pertencentes a esta P.I. que viviam mendingando pelas ruas de Santos e São Paulo, e, se isso não continua, é porque procurei, dispondo de parcos meios que possuia, incrementar a produção, como está provado pelo material agricula e sementes chegadas a este Pôsto [...]. Devo comunicar que estes índios acima citados continuam impedindo que se faça roças em qualquer parte desta reserva, causando daí grande presuiso ao Pôsto que se tolido de aumentar suas lavouras, dando cumprimento, assim, a Circular do S.P.I. que consiste os Encarregados de Pôsto a aumentar, ou melhor, produzir ao menos para seu próprio sustento (MUSEU DO ÍNDIO, carta de 1950, n.p.).

Por outro lado, os documentos que consultamos também sinalizam a contrapartida, isto é, que os ameríndios assistidos resistiam aos encarregados do P. I. Itanhaém. Isso pode ser visto no trecho de uma carta, de autoria desconhecida, enviada pelo encarregado do supracitado posto à $5^{\text {a }}$ Inspetoria Regional:

Ciente do bom cumprimento que destas as ordens desta chefia a respeito dos incidentes, cumpre agora aguardar oportunidade em que se providenciara pessoa capas de conduzir os índios criminosos para o P. I. Icatu, onde cumprirão pena de internação correcional, conforme o Regulamento (MUSEU DO ÍNDIO, carta de 1941, n.p.).

No fragmento acima transcrito, destaca-se a menção feita pelo autor à condução de "índios criminosos" ao PI Icatu. De acordo como o Relatório Figueiredo (1967)15 - resultado do trabalho feito pela Comissão de Investigação do Ministério do Interior, do qual o Procurador-Geral Jáder Figueiredo Corrêa era responsável - , existiam, assim como em Postos

\footnotetext{
${ }^{15}$ Esse documento, que ficou conhecido como Relatório Figueiredo, contém mais de 7.000 páginas, em que se revelaram os crimes cometidos pelos agentes do Estado contra os índios (COMISSÃO NACIONAL DA VERDADE, 2014).
} 
situados em outros estados da Federação, cadeias nos Posto Indígenas de Vanuíre, Capitão lacri e Icatu. Nesses espaços, independentemente do Posto em que estivessem alocados, encontravam-se os indígenas que cometeram algum delito ou que eram vistos como perigosos.

O poder discricionário exercido pelos agentes do Serviço revela-se de modo mais ostensivo, seja no julgamento pessoal ou na determinação em dispor sobre a vida daqueles que eram assistidos. E mais: a opressão aos indígenas era operada também no cerceamento de suas relações ao estipular como deveriam dispor do ambiente, sob a pena de degredo à distância de parentes e afins. Em outra carta, que data de 18 de março de 1950, o encarregado, Tonollier, indica que os índios da aldeia Bananal resistiram a entregar parte da produção do arroz para o Posto. Seguem as palavras do encarregado:

O arros já está quase bom de colhêta, mas os índios continuam dispostos a não permitir que o Pôsto tire desse arros a sua parte, ou seja, a metade, pois, alegam que o Pôsto cortou alimento que Ihes via dando e, que agóra, eles não dão cousa alguma para o referido Pôsto. De modo que diante disto nada posso fazer, mas também não me importo, pois fico mais do nunca ter acabado com a grande miséria existente naquela Aldeia. O referido arros dará quase cem sacos, se não der mais, pois se fora eu que o colhêsse daria duzentos (MUSEU DO ÍNDIO, carta de 1950, n.p.).

Porém, os meios contundentes também foram usados pelos índios do Bananal para assegurar a sua liberdade. Isso está registrado em três telegramas, encaminhados pelo encarregado do posto à $5^{\text {a }}$ Inspetoria Regional:

QUATRO INDIOS REBELDES NAO PERMITEM CONTINUAR FUNCIONANDO O POSTO AREA INDIGENA VG EM VISTA NAO RECEBEREM ASSISTENCIA PT SITUACAO GRAVISSIMA PT ESTOU VIDA EM PERIGO AGUARDO INSTRUCOES URGENTES AGRINDIOS ITANHAEM (MUSEU DO ÍNDIO, telegrama de oito de março de 1952, n.p.).

FUI AGREDIDO INDIOS VG FERIMENTOS LEVES PT ESTOU PROVIDENCIANDO PRISÃO DELEGACIA LOCAL TODOS OS ÍNDIOS REBELDES QUE PROJETAM IR AO RIO DE JANEIRO 
SITUAÇÃO INSUSTENTÁVEL AGRINDIOS ITANHAÉM (MUSEU DO ÍNDIO, telegrama de dois de abril de 1952, n.p.).

N.41. TENHO DETIDO UMA FAMILA COMPOSTA DEZ PESSOAS PT NÃO PODEREI DEIXA LA AQUI POIS CONFESSARAM POLICIA COMPLO PARA ASSASSINAR ME PT CRENTE VOSSO NUMERO 84 ESTE POSTO CUSTEARA DESPESA DA MESMA VG POREM SOLICITO VOS MANDARDES O CAMINHAO DESSA IR A SAO PAULO PARA EU CONDUSIR DITOS REBELDES VG CUJA DESPESAS GASOLINA CAMINHAO E CHOFER MESMO CORRERAO POR CONTA DESTA POSTO PT AGUARDO RESPOSTA URGENTE PARA COMBINAR VINDA CAMINHAO AGRINDIOS ITANHAEM (MUSEU DO ÍNDIO, telegrama de 10 de maio de 1952, n.p.).

Outra evidência é a carta enviada por Renato Azzi, então diretor substituto do supracitado Posto Indígena, à sede da $7^{\mathrm{a}}$ Inspetoria, no dia 26 de junho de 1953, na qual pede uma intervenção quanto ao caso em que o capitão Pedro dos Santos Oliveira, cacique da aldeia Rio Comprido, acompanhado de sua parentela, apareceu no PI Peruíbe para comunicar que eles retornariam às terras das quais foram expulsos, situadas na cabeceira do Rio do Azeite, denominada pelos funcionários "Gleba A, Zona 2 do Perímetro II". Azzi revela que "os índios Guarany estão constituindo sérios problemas para esta administração", pois tais terras foram "concedidas ao senhor Manoel Leite Praça e já demarcadas, tem sua área invadida pelos Guarany que habitam as imediações". O autor ainda comenta que se tentou realocá-los na aldeia Bananal, próxima ao citado perímetro, mas eles permaneceram irredutíveis em sua posição.

Por fim, nos arquivos do Museu do Índio, há outra informação na qual consta que um funcionário do SPI é acusado de corrupção. Nessa fonte primária, de autoria desconhecida e encaminhada para José Maria da Gama Malcher, está escrito que um servidor, chamado Iridiano, havia fraudado as tabelas dos gastos do PI Peruíbe (MUSEU DO íNDIO, carta de 1953, n.p.). Um dado trecho da carta de Deocleciano de Souza Nenê a José Maria da Gama Malcher, diretor do SPI, também revela tal prática. No excerto, o autor da missiva diz que: 
O senhor Romeu Muniz é o Prefeito de Itariri, e já até foi servidor do SPI, segundo informações aqui obtidas [...] corre contra ele um processo pela Secretaria de Agricultura, justamente sobre questões das terras que ele quer que os índios permaneçam, estando, por isso com a Secretária de Agricultura contraria a ele, que vale dizer, e reconhecer [...] (MUSEU DO ÍNDIO, carta de 1953, n.p.).

Então, as áreas habitadas pelos Tupi e Guaranis continuariam a ser alvo de cobiça e de sucessivas invasões. A propósito, um relatório do SPI, datado de 1964, recomenda a demarcação das terras da aldeia Bananal, uma vez que seus limites teriam propositalmente desaparecido, e as terras, invadidas e apropriadas por posseiros (MUSEU DO ÍNDIO, relatório de 1964).

\section{Sai o SPI, entra a FUNAI}

Em 1941, o conhecido etnólogo alemão Curt Nimuendaju, então funcionário do SPI, escreveu para José Maria da Gama Malcher, diretor da instituição no período de 1950 a 1954; na carta, declarava suas impressões acerca da política indigenista daquele momento. Conforme o etnólogo:

O regulamento do SPI protege as instituições dos índios, mas, como já disse, uma tolerância apenas não é suficiente, e nos postos do SPI reina, por forças de circunstâncias, um ambiente francamente sufocador de toda particularidade étnica do índio (NIMUENDAJU, 1941 apud ROCHA FREIRE, 2014, p. 11).

Já no final da década de 1950, o também etnólogo Carlos Araújo Moreira Neto (1959), pesquisador do Museu Paraense Emílio Goeldi, redigiu um relatório no qual revela o extermínio de grupos Kaiapó, o que coloca em xeque o trabalho do SPI. E, por fim, o Relatório Figueiredo registra as seguintes palavras:

Nesse regime de baraço e cutelo viveu o SPI muitos anos. A fertilidade de sua cruenta história registra até crucificação, os castigos físicos eram considerados fato 
natural nos Postos Indígenas (RELATÓRIO FIGUEIREDO, 1967, p. 03).

Um ano depois, em 1968, o SPI foi extinto e, em seu lugar, instituiu-se a Fundação Nacional do Índio (FUNAI). Assim, o governo brasileiro reedita o discurso de que a finalidade da nova instituição seria a proteção e a integração dos povos indígenas à sociedade nacional. No entanto, o que se seguiu foi uma política indigenista repleta de contradições: a FUNAI, nas palavras de Davis e Menget, carregava consigo uma política indigenista que

[...] falsifica tudo que é cientificamente conhecido sobre a natureza das relações índio-brasileiro ao longo dos quatro séculos, como também é um gritante e consciente afastamento dos princípios razoáveis e humanitários da política de Rondon (DAVIS e MENGET, 1981, p. 40).

Nesse contexto político, muitas famílias Tupi e Guarani não encontraram dificuldades em estabelecer suas aldeias junto à Serra do Mar do litoral paulista, e especuladores se dispunham a protegê-los, aparentemente, "em troca de serem reconhecidos como senhores das terras ocupadas por eles" (AZANHA e LADEIRA, 1988, p. 7). Contudo, a partir dos anos 1970, a situação dos indígenas que viviam no litoral paulista mudou, com a construção da Rodovia Rio-Santos. Aliás, como demonstrei anteriormente, as melhorias de acesso à região tiveram início no começo do século XX, com a instalação da estrada de ferro. Mas, segundo Frank Goldman e Azis Simão (1958), o litoral paulista, a partir da década de 1950, com a abertura de estradas de rodagem e outras obras públicas - a Rodovia Padre Manuel da Nóbrega, a Ponte Pênsil e, logo depois, a Ponte José Menino, que liga São Vicente aos demais municípios da Baixada Santista - passou a receber um significativo número de migrantes e turistas, sendo a principal característica destes últimos o chamado "turismo de final de semana", ou as "temporadas de verão".

Como expressa Ladeira (2007), a nova conjuntura para os índios no Litoral Paulista e no Vale do Ribeira pode ser caracterizada da seguinte forma: 1) a eles eram negados quaisquer direitos sobre as terras que 
Vladimir Bertapeli - Primeiras notas sobre a relação entre indígenas e o Serviço de Proteção....

ocupavam, porque eram vistos como nômades ou errantes, remanescentes de aldeias em extinção e que não "lutavam" por terra; 2) eles eram vistos como "aculturados", e, com isso, afirmava-se que estavam integrados à sociedade nacional. Assim, carregando aonde iam a pecha de "aculturados", "integrados" à sociedade nacional, ou, então, de "não mais índios", muitos deles preferiram se embrenhar no interior da Mata Atlântica; outros permaneceram nas proximidades dos antigos aldeamentos/PIs e, por último, outros foram viver nas zonas periféricas das cidades. Este é o caso emblemático de algumas famílias Tupi e Tupiguarani do litoral paulista e do Vale do Ribeira.

\section{Considerações finais}

Para desenvolver o que aqui propomos, foi necessário esquadrinhar um conjunto de fontes primárias, cuja fragmentação tornou-se um desafio que requer especial atenção. Pois, se quisermos melhor compreender o protagonismo indígena, especialmente daqueles que passaram parte de suas vidas sob os cuidados e o controle do SPI no litoral paulista, entre os anos de 1923 e 1967, é importante que se tenha em mente as condições fragmentárias em que se encontram os documentos em questão. Portanto, mais uma vez lembramos que esses documentos escritos são fragmentos históricos devidos à intermitência do trabalho do SPI no litoral de São Paulo; é, além disso, o que sobrou do supracitado incêndio que, em meados de 1967, destruiu parte do acervo do SPI.

Mas, os depoimentos de alguns idosos Tupi e Tupi-guarani que apresentamos, apesar de serem poucos e de também terem como característica a fragmentação da memória, manifestam-se como um importante recurso que pode ser utilizado na compreensão da relação entre indígenas e o SPI daquela localidade. Consequentemente, isso remonta a Jean e John Comaroff (2010, p. 20): "tudo que o historiador da cultura pode 'ver' são fragmentos de uma época - exatamente como o etnógrafo 'vê' apenas fragmentos de um campo cultural".

Por ora, concluímos que é possível extrair de antemão alguns apontamentos que, devido aos limites supracitados, demandam estudos 
de maior envergadura. Por certo, dentre esses sobressaem o processo pelo qual as terras onde viviam os indígenas da região foram reduzidas e transformadas em "terras devolutas"; os percalços do SPI em fixar um Posto Indígena no litoral de São Paulo, bem como as atividades suspeitas dessa instituição no litoral paulista; as relações entre os funcionários do Serviço com os políticos e empresários locais; e, por fim e não menos importante, o protagonismo dos indígenas frente à ação do SPI na costa litorânea de São Paulo.

Referências bibliográficas

Fontes primárias

BIBLIOTECA NACIONAL DO RIO DE JANEIRO. Relatório anual da Secretaria da Agricultura do Estado de São Paulo, 1914.

. Relatório anual do SPI ao Ministério da Agricultura, 1923.

Relatório anual do SPI ao Ministério da Agricultura, 1927.

Relatório anual do SPI ao Ministério da Agricultura, 1928.

MUSEU DO ÍNDIO. Ata de instalação do Serviço de Proteção aos Índios, 1910. Microfilme 001.

Carta do advogado J. da Matta Cardim ao Ministério do Trabalho, Indústria e Comércio, 1930. Microfilme 001.

Carta do inspetor da $5^{\text {a }}$ Inspetoria Regional [não assinada] ao encarregado do PI da Bananal, 27/05/1941. Microfilme 001.

Relatório escrito por Joaquim Fausto Prado, chefe da $5^{\text {a }}$ Inspetoria Regional, e endereçada ao inspetor Érico Sampaio, 29/11/1948. Microfilme 11.

. Carta do inspetor Victor Tonollier. 1949. Microfilme 021.

Telegrama do inspetor Victor Tonollier, 28/03/1952. Microfilme 021.

Telegrama do inspetor Victor Tonollier, 02/04/1952. Microfilme 021.

Telegrama do inspetor Victor Tonollier, 10/05/1952. Microfilme 021. 
Relatório do vereador da Câmara Municipal de Itariri, senhor Milton Fraga Moreira, à $5^{\circ}$ Regional do SPI. 08/08/1953. Microfilme 021.

Carta do vereador da Câmara Municipal de Itariri, senhor Milton Fraga Moreira, a Deocleciano de Souza Nenê, chefe da $5^{\text {a }}$ Inspetoria Regional, 04/11/1953. Microfilme 30.

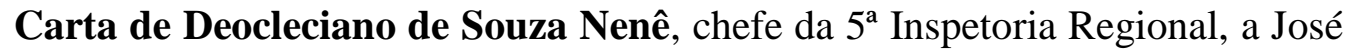
Maria da Gama Malcher, diretor do SPI, 04/11/1953. Microfilme 30.

Carta (de autor desconhecido) a José Maria da Gama Malcher, diretor do SPI, 12/09/1953. Microfilme 33.

Ofício: Transferência de responsabilidade do P.I. Itanhaém da $5^{\text {a }}$ Inspetoria Regional à Diretoria do Rio de Janeiro. 4/11/1953. Microfilme 28.

. Relatórios do SPI ao Ministério da Agricultura, Indústria e Comércio, 19151960. Microfilme 001.

Carta do diretor substituto do Posto Indígena Peruíbe, Renato Azzi, ao Departamento de Imigração e Colonização, 26/07/1953. Microfilme 800.

Carta do chefe da $5^{\mathbf{a}}$ Inspetoria Regional, Deocleciano de Souza Nenê, ao Diretor do SPI, José Maria da Gama Malcher, 1953. Microfilme 33.

Carta do funcionário do SPI, Benamour B. Fontes, à $5^{\mathrm{a}}$ Inspetoria Regional, 1959. Microfilme 800.

Relatório da aldeia José de Anchieta (Peruíbe) à $7^{\mathrm{a}}$ Inspetoria Regional, 1964. Microfilme 375.

Relatório Jáder Figueiredo Corrêa, 1967, v. 01, v. 23, v. 30.

\section{Demais referências}

ANTUNHA BARBOSA, P. A. Relatório etno-histórico referente à ocupação Guarani na região do Vale do Ribeira, elaborado por Pablo Antunha Barbosa (Portaria $\mathrm{n}^{\mathbf{o}}$ 586/PRES/FUNAI, de 19.04.2011). Brasília: FUNAI, 2011.

"Terra sem Mal" de Curt Nimuendaju e a "Emigração dos Cayuáz" de João Henrique Elliot: notas sobre as "migrações" guarani no século XIX. Tellus, Campo Grande, n. 24, p. 121-158, 2013.

AZANHA, G.; LADEIRA, M. I. Os índios da Serra do Mar. São Paulo: Nova Stella, 1988. 
Vladimir Bertapeli - Primeiras notas sobre a relação entre indígenas e o Serviço de Proteção....

CARNEIRO DA CUNHA, M. Legislação indigenista no século XIX. São Paulo: EDUSP/Comissão Pró-Índio, 1992.

CLASTRES, H. Terra sem Mal: o profetismo Tupi-Guarani. São Paulo: Brasiliense, 1978.

CLASTRES, P. A sociedade contra o Estado. São Paulo: Brasiliense, 1978.

CHAMORRO ARGÜELLO, C. G. Terra madura yvy araguyje: fundamentos da palavra Guarani. Dourados: UFGD, 2008.

COMAROFF, J.; COMAROFF, J. Ethnograph and historical imagination. Boulder: Westview Press, 1992.

_. Etnografia e imaginação histórica. Proa - Revista de Antropologia da Arte, v. 1 n. $2, \quad$ p. $\quad 1-72 \quad 2010 . \quad$ Disponível em: http://www.ifch.unicamp.br/proa/TraducoesII/comaroff.html . Acesso em: 23 jan. 2017.

CORREA, J. G. S. A ordem a se preservar: a gestão dos índios e o Reformatório Agrícola Indígena Krenak. 2000. 196 f. Dissertação (Mestrado em Antropologia Social) - Rio de Janeiro, Universidade Federal do Rio de Janeiro, [2000].

DALL'IGNA RODRIGUES, A. Diferenças fonéticas entre Tupi e Guarani. Curitiba: Empresa Gráfica Paranaense LTDA, 1945.

DANAGA, A. Os Tupi, os Mbya e os Outros: um estudo etnográfico da aldeia Renascer - Ywyt Guaçu. 2012. 134 f. Dissertação (Mestrado em Antropologia Social) - São Carlos, Universidade Federal de São Carlos, [2012].

DAVIS, S.; MENGET, P. Povos primitivos e ideologias civilizadas no Brasil. In. JUNQUEIRA, C.; CARV ALHO, E. A. (Org.). Antropologia e indigenismo na América Latina. São Paulo: Cortez, 1981. p. 37-65.

ELLIOT, J. H. A emigração dos cayuaz. Revista do Instituto Histórico e Geographico do Brasil, Rio de Janeiro, tomo XIX, 1898.

FAUSTO, C. Os índios antes do Brasil. Rio de Janeiro: Zahar, 2010.

FERNANDES, F. A organização social dos Tupinambá. Brasília: EDUNB, 1989.

A função social da guerra na sociedade Tupinambá. São Paulo: Globo, 2006.

GAGLIARDI, J. M. O indígena e a República: estudo a respeito do Serviço de Proteção aos Índios. 1985. Dissertação (Mestrado em Ciências Sociais) - São Paulo, Pontifícia Universidade Católica, [1985].

GOLDMAN, F.; SIMÃO, A. Itanhaém: estudos sobre o desenvolvimento econômico e social de uma cidade litorânea. Boletim de Sociologia II. São Paulo, n. 226, 1958. 
GOODY, J. A domesticação da mente selvagem. Petrópolis: Vozes, 2012.

LADEIRA, M. I. O caminhar sob a luz: território Mbyá a beira do oceano. 1992. 199 f. Dissertação (mestrado em Ciências Sociais) - Programa de Pós-Graduação em Ciências Sociais da Pontifícia Universidade Católica de São Paulo, [1992].

O caminhar sobre a luz: o território Mbyá à beira do oceano. São Paulo: EDUNESP, 2007.

Espaço geográfico Guarani-Mbya: significado, constituição e uso. São Paulo/Maringá: EDUSP/EDUEM, 2010.

LADEIRA, M. I. et al. Atlas das terras indígenas no Sul e Sudeste do Brasil - 2015. São Paulo: CTI/IPHAN, 2015.

MELIÁ, B. A Terra sem Mal dos Guarani: economia e profecia. Revista de Antropologia, São Paulo, v. 33, p. 33-46, 1990.

MÉTRAUX, A. A religião dos Tupinambás e suas relações com a das demais tribos tupi-guarani. São Paulo: Editora Nacional/EDUSP, 1979.

MOREIRA NETO, C. A. Relatório sobre a situação atual dos índios Kayapó. Revista de Antropologia, São Paulo, v. 7, n. 1-2, p. 49-64, 1959.

NIMUENDAJU, C. As lendas de criação e destruição do mundo como fundamentos da religião Apapocúva-Guarani. São Paulo: Hucitec/USP, 1987.

OLIVEIRA FILHO, J. P. Uma etnologia dos “índios misturados?”: situação colonial, territorialização e fluxos culturais. Mana, Rio de Janeiro, n. 4, v. 1, p. 47-77, 1998.

Ensaios de antropologia histórica. Rio de Janeiro: Editora da UFRJ, 1999.

- Os instrumentos de bordo: expectativas e possibilidades do trabalho do antropólogo em laudos periciais. Revista Nanduty, Grandes Dourados, v. 1, n. 1, 2012.

PETRONE, P. Os aldeamentos paulistas. São Paulo: EDUSP, 1992.

PRICE, R. First-time: the historical vision of an afro-american people. Baltimore: John Hopkins Universty, 1983.

RIBEIRO, D. Política indigenista brasileira. Rio de Janeiro: Ministério da Agricultura/Serviço de Informação Agrícola, 1962.

Os índios e a civilização: a integração das populações indígenas no Brasil moderno. São Paulo: Companhia das Letras, 1996.

ROCHA FREIRE, C. A. Memória do SPI: textos, imagens e documentos sobre o 
Serviço de Proteção aos Índios (1910-1967). Rio de Janeiro: Museu do Índio, 2014.

SAHLINS, M. Ilhas de história. Rio de Janeiro: Zahar, 2003.

Cultura na prática. Rio de Janeiro: Editora da UFRJ, 2007.

Metáforas históricas e realidades míticas. Rio de Janeiro: Zahar, 2008.

SILVA, M. L. O. Terras devolutas e latifúndio: efeitos da Lei de 1850. Campinas: Editora da Unicamp, 2008.

SOUZA LIMA, A. C. O governo dos índios sobre a gestão do SPI. In. CARNEIRO DA CUNHA, M. (Org.) História dos índios do Brasil. São Paulo: Companhia das Letras, 1992.

Um grande cerco de paz: poder tutela, indianidade e formação do Estado no Brasil. Petrópolis: Vozes, 1995.

TIDEI DE LIMA, J. F. A ocupação da terra e a destruição dos índios na região de Bauru. 1978. 2 v. Dissertação (Mestrado em História Social) - São Paulo, Universidade de São Paulo, [1978].

VANSINA, J. Oral tradition: a study in historical methodology. Aylesbury: Penguin, 1973.

Recebido em: 20/05/2017 * Aprovado em: 23/11/2017 * Publicado em: 31/12/2017 